\title{
Factors Influencing the Release of Renin in Patients under Chronic Dialysis Treatment
}

\author{
Hrroshi Kaneda, Masato Tashiro, Toyoaki Murata, Jun \\ Matsumoto, Mutsuo Takeuchi* and Takeshi Haruyama $\dagger$ \\ Clinic of Renal Disease, Iwaki-Kyoritsu General Hospital, \\ I waki, 973, *Department of Urology, Iwaki-Kyoritsu General \\ Hospital, Iwaki 973 and †Department of Internal Medicine, \\ Joban City Hospital, Iwaki 972
}

\begin{abstract}
Kaneda, H., Tashiro, M., Murata, T., Matsumoto, J., Takeuchi, M. and Hardyama, T. Factors Infuencing the Release of Renin in Patients under Chronic Dialysis Treatment. Tohoku J. exp. Med., 1979, 129 (2), 177-182Plasma renin activities (resting PRA, post-dialysis PRA and $\triangle \mathrm{PRA}$ ) were studied in 61 patients under chronic dialysis treatment. Removed sodium and removed water were estimated at each dialysis. $\triangle \mathrm{PRA} /$ removed-sodium and $\triangle \mathrm{PRA} / \mathrm{removed}$ -water were calculated as indices in response to the removal of sodium and water during the dialysis. 1) Resting PRA (pre-dialysis PRA) was positively correlated to $\triangle \mathrm{PRA} /$ removed-sodium, $\triangle \mathrm{PRA} /$ removed-water, serum osmolality, and diastolic blood pressure, but negatively to serum sodium concentration, age, and pulse pressure/diastolic blood pressure. Statistically significant factors controlling the resting PRA were $\triangle \mathrm{PRA} /$ removed-sodium, $\triangle \mathrm{PRA} /$ removed-water, and serum sodium concentration. Resting PRA was slightly correlated to diastolic blood pressure and age. 2) Post-dialysis PRA was significantly correlated to the resting PRA, $\triangle \mathrm{PRA} /$ removed-sodium, $\triangle \mathrm{PRA} /$ removed-water, serum sodium concentration, and age, but not to the blood pressure indices. —_ PRA in dialysed patients; releasability of renin and dialysis treatment
\end{abstract}

Although the renin-angiotensin-aldosterone system in essential hypertension has been extensively investigated (Laragh et al. 1972; Brunner et al. 1973; Laragh 1973; Abe et al. 1975, 1977), the studies on patients under long-term hemodialysis, especially those concerning the effect of dialysis on plasma renin activity (PRA), are scarce in the literature (Laragh et al. 1973; Kaneda et al. 1978a, b).

We have noticed that PRA after dialysis (post-dialysis PRA) was higher than that before dialysis(pre-dialysis PRA), though blood pressure was decreased during the post-dialysis period in most patients. Furthermore, patients usually became anuric as the dialysis treatment was prolonged, and consequently the removal of fluid and electrolytes, especially of sodium and water, from the body was attained only by the dialysis treatment. The patients in this condition also showed post-dialysis hyperreninemia (Kaneda et al. 1978a).

From these observations, we presumed that the dialysis treatment has a

Received for publication, September 30, 1978. 
decisive effect on PRAs in dialysed patients. In this study, factors which affect the increase of PRA during the dialysis were investigated.

\section{Materials and Methods}

Sixty-one patients ( 36 males and 25 females) under chronic dialysis treatment were subjected to this study. Their age ranged from 15 to 69 years (mean 42.8), and the duration of dialysis ranged from 3 to 83 months (mean 19.8). Their underlying diseases were chronic glomerulonephritis (60 patients) and Alport's syndrome (1 patient). All patients had stopped hypotensive medications and had been treated only by hemodialysis at least for 3 months. The hemodialysis was performed through arteriovenous fistula two or three times per week, the total dialysis time being 14 to $18 \mathrm{hr}$ per week. The dialysate supply system was composed of a 50 liters tank and a recirculation system, so that the amount of fluid and electrolytes dialysed out of the body were easily calculated at the end of the dialysis. Removed sodium, removed water, and other removed substances were routinely measured after each dialysis. PRA was determined by radioimmunoassay of angiotensin I (Abe et al. 1972; normal range, 5.0 to $30.0 \mathrm{ng} / \mathrm{ml}$ ) before and after the dialysis once a month. Serum sodium concentration and plasma osmolality were also measured monthly before and after the dialysis. These measurements were repeated for serial three months in all patients. The mean values of three months were used for each patient. daily).

All patients were on a restricted salt intake (approximately 100 to $120 \mathrm{mEq}$ of sodium

In our clinic, large amounts of sodium ( 400 to $800 \mathrm{mEq}$ ) and water (2 to 4 liters) were removed by each dialysis (Kaneda et al. 1978a) and such a removal was repeated two or three times per week.

\section{Results and Discussion}

The results are summarized in Tables 1-4. $4 \mathrm{PRA}$ (post-dialysis PRA minus pre-dialysis PRA) was positively correlated to $\triangle \mathrm{PRA} /$ removed-water, $\triangle \mathrm{PRA} /$ removed-sodium, and resting $\mathrm{PRA}$, but negatively to sermm sodium concentration (Table 1).

The ratio $4 \mathrm{PRA} /$ removed-sodium was positively correlated to $\triangle \mathrm{PRA}$, postdialysis PRA, and resting PRA, but negatively to serum sodium concentration after dialysis and the duration of dialysis (Table 2a).

APRA/removed-water was positively correlated to APRA, post-dialysis PRA, and resting PRA, but negatively to serum sodium concentration before dialysis and the duration of dialysis (Table $2 b$ ).

Resting PRA was postively correlated to $\Delta \mathrm{PRA} /$ removed-sodium, $\Delta \mathrm{PRA}, \triangle \mathrm{PRA} /$ removed-water, serum osmolality, and diastolic blood pressure, but negatively to serum sodium concentration, age of patient and pulse pressure/diastolic blood pressure (Table 3).

Post-dialysis PRA was positively correlated to resting PRA, APRA/removedsodium, $\triangle \mathrm{PRA}$, and APRA/removed-water, but negatively to serum sodium concentration after the dialysis and age of patient (Table 4).

Thus, APRA, $4 \mathrm{PRA} /$ removed-sodium and $\triangle \mathrm{PRA} / \mathrm{removed}$-water were the factors which showed positive correlations to both resting and post-dialysis PRAs. They can he used as indices to the releasability of renin against the stimulation of 
TABLE 1. Correlation coefficients and levels of significance between $\triangle P R A$ and the parameters

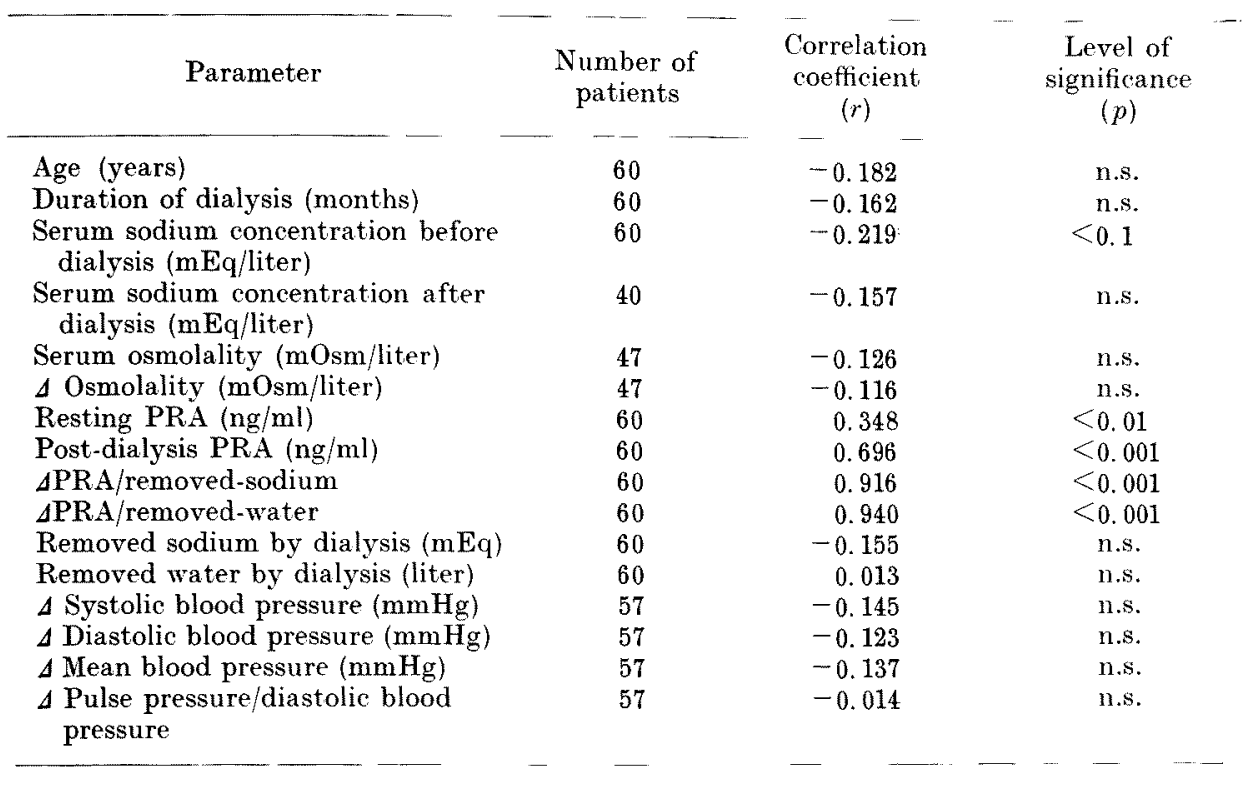

TABLE 2a. Correlation coefficients and levels of significance between. $\triangle P R A$ /removed-sodium and the parameters

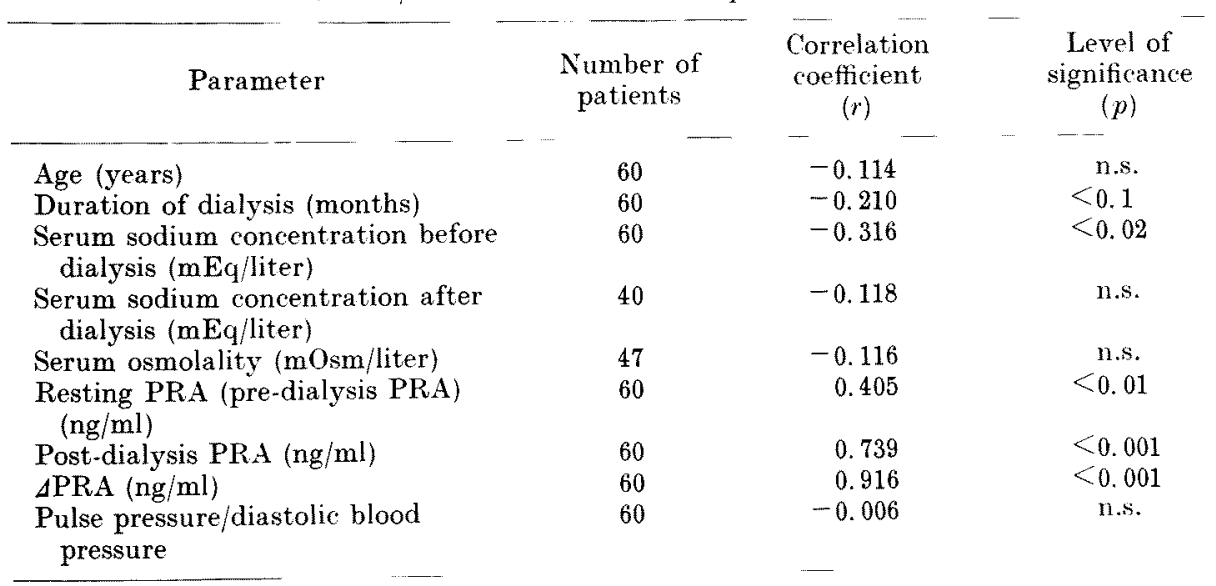

dialysis treatment. $\triangle \mathrm{PRA}$ implies the responsiveness of renin to the stimulation of dialysis, while $\triangle \mathrm{PRA} /$ removed-sodium and $\triangle \mathrm{PRA} /$ removed-water mean the responsiveness of renin to sodium and water removed by dialysis.

$\triangle \mathrm{PRA} /$ removed-sodium and $\triangle \mathrm{PRA} /$ removed-water were also significantly correlated to serum sodium concentration.

The correlation coefficients of $\triangle \mathrm{PRA} /$ removed-sodium to resting and postdialysis PRAs were significantly higher than those of $\Delta \mathrm{PRA} / \mathrm{removed}$-water. 
TABLE $2 \mathrm{~b}$. Correlation coefficients and levels of significance between $\triangle P R A /$ removed-water and the parameters

\begin{tabular}{lccc}
\hline \multicolumn{1}{c}{ Parameter } & $\begin{array}{c}\text { Number of } \\
\text { patients }\end{array}$ & $\begin{array}{c}\text { Correlation } \\
\text { coefficient } \\
(r)\end{array}$ & $\begin{array}{c}\text { Level of } \\
\text { significance } \\
(p)\end{array}$ \\
\hline $\begin{array}{l}\text { Age (years) } \\
\text { Duration of dialysis (months) }\end{array}$ & 60 & -0.113 & n.s. \\
$\begin{array}{l}\text { Serum sodium concentration before } \\
\text { dialysis (mEq/liter) }\end{array}$ & 60 & -0.229 & $<0.1$ \\
$\begin{array}{l}\text { Serum sodium concentration after } \\
\text { dialysis (mEq/liter) }\end{array}$ & 40 & -0.253 & $<0.05$ \\
$\begin{array}{l}\text { Serum osmolality (mOsm/liter) } \\
\text { Resting PRA (pre-dialysis PRA) }\end{array}$ & 47 & 0.020 & n.s. \\
(ng/ml) & 60 & -0.052 & n.s. \\
$\begin{array}{l}\text { Post-dialysis PRA (ng/ml) } \\
\text { SPRA (ng/ml) }\end{array}$ & 60 & 0.278 & $<0.05$ \\
Pulse pressure/diastolic blood & 60 & 0.658 & $<0.001$ \\
pressure & 60 & 0.940 & $<0.001$ \\
\hline
\end{tabular}

TABLE 3. Correlation coefficients and levels of significance between resting PRA and the parameters

\begin{tabular}{lccc}
\hline Parameter & $\begin{array}{c}\text { Number of } \\
\text { patients }\end{array}$ & $\begin{array}{c}\text { Correlation } \\
\text { coefficient } \\
(r)\end{array}$ & $\begin{array}{c}\text { Level of } \\
\text { significance } \\
(p)\end{array}$ \\
\hline $\begin{array}{l}\text { Age (years) } \\
\text { Duration of dialysis (months) }\end{array}$ & 61 & -0.235 & $<0.1$ \\
$\begin{array}{l}\text { Serum sodium concentration before } \\
\text { dialysis (mEq/liter) }\end{array}$ & 60 & 0.085 & n.s. \\
Serum osmolality (mOsm/liter) & 61 & -0.270 & $<0.05$ \\
APRA (ng/ml) & 68 & 0.272 & $<0.1$ \\
APRA/removed-sodium & 60 & 0.348 & $<0.01$ \\
APRA/removed-water & 60 & 0.405 & $<0.01$ \\
Removed sodium by the preceding & 61 & 0.278 & n.s. \\
dialysis (mEq) & & 0.048 & n.s. \\
Removed water by the preceding & 61 & 0.208 & n.s. \\
dialysis (liters) & & & $<0.1$ \\
Systolic blood pressure (mmHg) & 61 & -0.018 & n.s. \\
Diastolic blood pressure (mmHg) & 61 & 0.211 & $<0.1$ \\
Mean blood pressure (mmHg) & 61 & 0.139 & \\
Pulse pressure/diastolic blood & 61 & -0.224 & \\
pressure & & & \\
\hline
\end{tabular}

This indicates that $\triangle \mathrm{PRA} / \mathrm{removed-sodium} \mathrm{plays} \mathrm{a} \mathrm{more} \mathrm{important} \mathrm{role} \mathrm{in} \mathrm{the}$ release of renin than does $\triangle \mathrm{PRA} /$ removed-water in patients under long-term dialysis.

In usual dialysis treatment, the intervals of dialysis were two or three days. Foods and drinks taken in these intervals may have some influence on the PRAs at the next dialysis. But the fact that the resting PRA is influenced to some extent by $\triangle \mathrm{PRA} /$ removed-sodium and $\triangle \mathrm{PRA} /$ removed-water in the preceding dialysis implies that the sodium and water balance is dependent partly on the preceding dialysis and that the influence of meals is not so great. 
TABLE 4. Correlation coefficients and levels of significance between post-dialysis PRA and the parameters

\begin{tabular}{|c|c|c|c|}
\hline Parameter & $\begin{array}{c}\text { Number of } \\
\text { patients }\end{array}$ & $\begin{array}{c}\text { Correlation } \\
\text { coefficient } \\
(r)\end{array}$ & $\begin{array}{c}\text { Level of } \\
\text { significance } \\
(p)\end{array}$ \\
\hline Age (years) & 60 & -0.240 & $<0.1$ \\
\hline Duration of dialysis (months) & 60 & -0.020 & n.s. \\
\hline $\begin{array}{l}\text { Serum sodium concentration after } \\
\text { dialysis }(\mathrm{mEq} / \text { liter })\end{array}$ & 40 & -0.358 & $<0.02$ \\
\hline $\begin{array}{l}\text { Serum osmolality before dialysis } \\
\text { (mOsm/liter) }\end{array}$ & 46 & -0.057 & n.s. \\
\hline$\triangle \mathrm{PRA}(\mathrm{ng} / \mathrm{ml})$ & 60 & 0.696 & $<0.001$ \\
\hline$\triangle \mathrm{PRA} / \mathrm{removed}$-sodium & 60 & 0.739 & $<0.001$ \\
\hline$\Delta \mathrm{PRA} /$ removed-water & 60 & 0.658 & $<0.001$ \\
\hline $\begin{array}{l}\text { Resting PRA (pre-dialysis PRA) } \\
(\mathrm{ng} / \mathrm{ml})\end{array}$ & 58 & 0.884 & $<0.001$ \\
\hline Removed sodium by dialysis (mEq) & 60 & -0.125 & n.s. \\
\hline Removed water by dialysis (liters) & 58 & 0.005 & n.s. \\
\hline Systolic blood pressure $(\mathrm{mmHg})$ & 57 & -0.063 & n.s. \\
\hline Diastolic blood pressure ( $\mathrm{mmHg}$ ) & 57 & -0.050 & n.s. \\
\hline Mean blood pressure (mmHg) & 57 & -0.052 & n.s. \\
\hline $\begin{array}{l}\text { Pulse pressure/diastolic blood } \\
\text { pressure }\end{array}$ & 57 & 0.012 & n.s. \\
\hline
\end{tabular}

As for the serum sodium concentration and the resting PRA, low serum sodium concentration were usually accompanied by high levels of resting PRA. It can be said that PRA is mainly determined by the sodium status in the body. The resting PRA decreases with age. These findings are in accord with Abe et al. (1975) but not with Weidmann and Maxwell (1975).

The post-dialysis PRA was most closely correlated to resting PRA, followed by $\triangle \mathrm{PRA} /$ removed-sodium, $\triangle \mathrm{PRA} / \mathrm{removed}$-water, and serum sodium concentration. Between the post-dialysis PRA and blood pressure indices, no significant correlations were found.

\section{Acknowledgment}

We gratefully acknowledge Prof. Kaoru Yoshinaga, and Dr. Keishi Abe, the Second Department of Internal Medicine, Tohoku University School of Medicine, Sendai, for their advice on this study. Our thanks are also due to Dr. Yasuo Hatakeyama, Director of the Iwaki-Kyoritsu General Hospital, Iwaki and Dr. Nobuhide Mimura, Director of the Department of Nephrology, Toranomon General Hospital, Kanagawa.

\section{References}

1) Abe, K., Otsuka, Y., Saito, T., Chin, B.S., Aoyagi, H., Miyazaki, S., Irokawa, N., Seino, M., Miura, Y., Ono, I., Minai, K., Kobayashi, K., Seki, K. \& Yoshinaga, K. (1972) Measurement of plasma renin activity by angiotensin I radioimmunoassay: a modification of Haber's method. Jap. circulat. J., 36, 741-749.

2) Abe, K., Irokawa, N., Aoyagi, H., Memezawa, H., Yasujima, H., Otsuka, Y., Saito, T. \& Yoshinaga, K. (1975) Circulating renin in essential hypertension: an evaluation of its significance in the Japanese population. Amer. Heart J., 89, 723-730.

3) Abe, K., Irokawa, N., Aoyagi, H., Seino, M., Yasujima, M., Ritz, K., Ito, T., Chiba, 
S., Sakurai, Y., Saito, K., Kusaka, T., Otsuka, Y., Miyazaki, S. \& Yoshinaga, K. (1977) Low renin hypertension - Is it a stage of essential hypertension? Tohoku J. exp. Med., $121,347-354$.

4) Brumner, H.R., Sealey, J.E. \& Laragh, J.H. (1973) Renin as a risk factor in essential hypertension: more evidence. Amer. J. Med., 55, 295-302.

5) Kaneda. H., Masato, T., Matsumoto, J., Haruyama, T., Murata, T. \& Abe, K. (1978a) Release of renal renin in patients under long-term dialysis treatment. Tohoku $J$. exp. Med., 127, 25-33.

6) Kaneda H., Matsumoto, J., Haruyama, T., Yoshikawa, K., Takeuchi, M. \& Murata, T, (1978b) Suppression of renin in diabetic patients under chronic dialysis treatment. Tohoku J. exp. Med., 127, 169-175.

7) Laragh, J.H., Baer, L., Brunner, H.P., Bühler, F.R., Sealey, J.E. \& Vaughan, E.D. (1972) Renin, angiotensin and aldosterone system in pathogenesis and management of hypertensive vascular disease. Amer. J. Med., 52, 633-652.

8) Laragh, J.H. (1973) Vasoconstriction-volume analysis for understanding and treating hypertension: The use of renin and aldosterone profiles. Amer. J. Med., 55, $261-274$.

9) Weidmann, P. \& Maxwell, M.H. (1975) The renin-angiotensin-aldosterone system in terminal renal failure, Kidney international, 8, 219-234. 